\title{
On-farm Safety and Efficacy Trial of Cow Start Calcium Bolus
}

\author{
John Lawlor ${ }^{1}$ *, Alan Fahey ${ }^{2}$, Enda Neville ${ }^{2}$, Alice Stack ${ }^{1}$, Finbar Mulligan² \\ ${ }^{1}$ Anchor Life Science Ltd., Co. Cork, Ireland \\ ${ }^{2}$ College of Health and Agricultural Sciences, University College Dublin, Dublin, Ireland
}

Email address:

john.lawlor@marigot.ie (J. Lawlor)

${ }^{*}$ Corresponding author

\section{To cite this article:}

John Lawlor, Alan Fahey, Enda Neville, Alice Stack, Finbar Mulligan. On-farm Safety and Efficacy Trial of Cow Start Calcium Bolus. Animal and Veterinary Sciences. Vol. 7, No. 6, 2019, pp. 113-118. doi: 10.11648/j.avs.20190706.11

Received: October 24, 2019; Accepted: November 18, 2019; Published: December 2, 2019

\begin{abstract}
The objective of this study was to evaluate both the safety, and efficacy of supplementation at calving with a combined oral calcium and anti-oxidant bolus on post-partum metabolic status, fresh cow energy status, vaginal mucous score and early lactation milk production performance. Multiparous $(\mathrm{n}=103)$ cows from 3 dairy herds in Ireland were enrolled in this study and randomly assigned to either a control $(\mathrm{CON}, \mathrm{n}=51)$ group or an oral bolus supplemented (BOL, $\mathrm{n}=52)$ group. CON cows received no oral boluses. BOL cows received 2 oral boluses, at 0 and 18 hours (hrs) after calving. Cows were fed a standard dry cow diet of second cut grass silage with supplemental pre-calving minerals, and fewer than $2.3 \%$ of all fresh cows $(\mathrm{n}=899)$ in these herds were treated for clinical milk fever (below target incidence level). Trial-eligible cows treated with IV calcium at calving were excluded from the trial. No adverse events associated with bolus safety were observed. The bolus was adminstered with ease and was well-tolerated by all animals. Calving and early lactation disease events were recorded. Metabolic status was evaluated by using milk ketone (beta hydroxybutyrate (BHBA)) testing at day 14 and day 21 postpartum. Cows in the BOL group recorded significantly lower milk BHBA levels $(0.46 \mathrm{mg} / \mathrm{dl})$ compared to CON cows $(0.67 \mathrm{mg} / \mathrm{dl}),(\mathrm{p}<0.0001)$. Milk yield, Milk Fat $\%$ and $\mathrm{kg}$, Milk Protein $\%$ and $\mathrm{kg}$, combined milk components (milk fat and milk protein $\mathrm{kg}$ ) and somatic cell counts (SCC) were recorded but no significant differences were observed. Results of this study indicate that the bolus is safe to use in post-partum dairy cows. Furthermore, cows responded favourably to treatment with the bolus with regard to improved metabolic status in the critical post-partum period. Results of this study suggest that supplementing dairy cows with oral boluses can have beneficial effects, even in dairy herds with a below-average incidence of hypocalcaemia.
\end{abstract}

Keywords: Hypocalcaemia, Calcium and Anti-oxidant Bolus, Metabolic Status

\section{Introduction}

Hypocalcaemia (milk fever), characterised by a decrease in blood calcium of the cow, is a common and costly metabolic disease of dairy cattle in the peri-partum period. At calving, the cow experiences a rapid increase in calcium demand for colostrum and milk production, however the ability of the cow to match this increase in demand can be delayed by $24-$ 48 hours. The excess calcium required is sourced from her digestive and skeletal systems through an upregulated calcium metabolism but the time delay between the sudden increase in demand and an increase in supply, results in a failure of the cow to maintain calcium homeostasis.

A total blood calcium of $2.1-2.5 \mathrm{mM}(8.5-10 \mathrm{mg} / \mathrm{dL})$ is normal in dairy cows, a blood calcium level of $1.4-2.0 \mathrm{mM}$ $(5.5-8.0 \mathrm{mg} / \mathrm{dL})$ is classified as sub-clinical hypocalcaemia and a blood calcium level of below $1.4 \mathrm{mM}(5.5 \mathrm{mg} / \mathrm{dL})$, clinical hypocalcaemia [1]. Dairy cows with clinical hypocalcaemia will present with signs such as staggered walking, inability to stand up, recumbency, and if left untreated, death. A recent calculation of the average cost of a case of clinical hypocalcaemia is approximately US\$250 [2]. Typical levels of clinical hypocalcaemia in dairy herds from various management systems are reported to be between 5 $7 \%[1,3,4]$. Clinical hypocalcaemia has been the subject of 
much research and has been found to be associated with a significant increased risk of dystocia, retained foetal membranes, displaced abomasum, ketosis and mastitis, all of which can have a negative impact on the cow's productive life $[1,5,6]$. Clinical hypocalcaemia has also been reported to delay the first ovulation after calving, delay uterine involution and increase the prevalence of endometritis [7].

As the level of understanding of clinical hypocalcaemia has increased, there has also been a growing recognition that cows with blood calcium levels above that of the clinical threshold $(1.4 \mathrm{nM})$ but below that of a normocalcaemic cow $(2.0 \mathrm{mM})$ still suffer negative effects of low blood calcium status, even if the cow does not show visible clinical signs. Martinez et al reported that cows with subclinical hypocalcaemia had reduced neutrophil oxidative burst and phagocytosis as markers of immune system functionality [8]. Recent research has reported the prevalence of sub-clinical hypocalcaemia in the US dairy herd at $41 \%$ of second lactation cows, reaching $54 \%$ by $5^{\text {th }}$ lactation, and $25 \%$ of $1^{\text {st }}$ lactation cows were recorded as having sub-clinical hypocalcaemia [9]. In grazing dairy cows approximately $33 \%$ of cows have been found to have subclinical hypocalcaemia on the day of calving [10].

Researchers have also linked lower blood calcium status with higher levels of lipolysis. It has been suggested that the combination of lower calcium status and higher levels of circulating non esterified fatty acids (NEFA) lead to higher levels of post parturient metabolic diseases. Reinhardt et al showed that cows with serum calcium $>2.0 \mathrm{mM}$ had lower serum non-esterified fatty acids (NEFA) concentrations than cows with serum calcium $<2.0 \mathrm{mM}$, which indicates that normocalcaemic cows are in better metabolic status than subclinically hypocalcaemic cows $[8,9]$.

Given the widespread prevalence and significant cost of sub-clinical hypocalcaemia, there is a growing focus on implementing prevention strategies at farm level. As identification of cows with sub-clinical disease is impractical (they display no symptoms), prevention of the disease is the only logical management strategy. A number of pre-partum dietary hypocalcaemia prevention strategies have been implemented in recent years such as low calcium strategy, negative DCAD and calcium binding. Another popular prevention strategy is the supplementation of cows at calving with an oral calcium source. This is designed to rapidly increase blood calcium levels post-calving when the cow is at highest risk of hypocalcaemia. Most oral calcium supplements have been in the form of drenches, gels, pastes and boluses. Calcium chloride has been a popular choice as a calcium source in oral calcium products as it supplies highly available calcium to the cow. Calcium chloride has been shown to increase blood calcium concentrations in dairy cows [11] and has also been shown to reduce the risk of clinical and sub-clinical hypocalcaemia and reduce the risk of displaced abomasum [12].

Calcium carbonate derived from the calcified remains of the marine red algal Lithothamnion spp. plant has been shown to be a highly soluble form of calcium that can quickly cross the rumen wall and significantly increase blood calcium levels compared to limestone-derived calcium carbonate and calcium propionate $(p<0.05)$ [13]. Blood calcium levels were also increased compared to limestone in a subsequent study $\mathrm{p}=0.027$ [14]. This calcium source also supplies calcium in a sustained release manner as it also supplies calcium at the small intestine for absorption at a second site (Rossi, personal communication).

Magnesium, also derived from the Lithothamnion spp plant, has also been shown to be present in a highly bioavailable form in a rumen environment, and is $99 \%$ soluble at a $\mathrm{pH}$ of 5.5. Recent research has shown a significant increase in urinary excretion of the $\mathrm{Mg}$ from Lithothamnion compared to finely ground magnesium oxide from other sources $(\mathrm{P}=<0.0001)$ [14].

Calcium chloride, calcium carbonate and magnesium derived from Lithothamnion, have been combined with rumen-protected Vitamin E and Selenium into a fat coated solid bolus (Cow Start Calcium Bolus, Anchor Life Science Ltd., Cork, Ireland.). When considering oral calcium treatments to prevent hypocalcaemia, Goff suggests that best results are obtained with doses of calcium between $50 \mathrm{~g}$ and $125 \mathrm{~g}$ calcium/dose [1]. A single Cow Start calcium bolus supplies $65 \mathrm{~g}$ of calcium and $4 \mathrm{~g}$ of $\mathrm{Mg}$. In order to ensure adequate bioavailability of calcium and an optimally functioning calcium metabolism, $4 \mathrm{~g}$ of rumen soluble Magnesium is also supplied by the Cow Start Calcium bolus. The rumen being recognised as the major and perhaps only site of $\mathrm{Mg}$ absorption in the cow [15, 16]. However, in certain circumstances, such as with high potassium $(\mathrm{K})$ diets, the limiting factor of an optimally functioning calcium metabolism can be $\mathrm{Mg}$ rather than calcium, as $\mathrm{K}$ can bind up $\mathrm{Mg}$ and reduce the efficiency of the cow's natural calcium homeostatic systems, which can delay the cows own ability to increase blood calcium. Therefore, in order to ensure adequate bioavailability of calcium, $4 \mathrm{~g}$ of rumen soluble Magnesium is also supplied by the Cow Start Calcium bolus.

In order to maintain an appropriate balance of antioxidants and reactive oxygen metabolites at calving, each Cow Start Calcium bolus delivers rumen protected 1200iu of Vitamin E and $4.65 \mathrm{mg}$ Selenium (Se) as two potent anti-oxidant sources. Dietary antioxidants, notably vitamin E and Se are important for their ability to neutralise reactive oxygen species and prevent peri-parturient diseases and reduce inflammation $[17,18]$. Vitamin E plasma concentrations are lowest between 1 week pre-partum and 2 weeks post-partum, inadequate dietary vitamin $\mathrm{E}$ or $\mathrm{Se}$ decreases neutrophil function during the peri-parturient period [19]. Decreased phagocytosis and intracellular killing by neutrophils occur in parallel with decreased DMI and decreased circulating vitamin E ( $\alpha$-tocopherol) concentration [20].

The objectives of this field study were to evaluate the safety of the Cow Start Calcium Bolus, and its effects on 1) post calving metabolic events 2 ) early lactation energy status, and 3) early lactation milk production performance on commercial dairy farms which had effective dry cow 
management procedures and protocols already in place.

\section{Materials and Methods}

\subsection{Study Population}

The study was conducted on 3 large commercial spring calving dairy farms in Ireland during the spring of 2018. All 3 herds were milking at least 250 cows, with a compact spring calving pattern and had excellent cow handling facilities. Each of the 3 herds took part in the national milk recording scheme, and were willing to administer the boluses according to trial protocol, as well as collecting and recording calving and cow health events. Bolus administration was a familiar procedure, and considered to be a component of routine management on these farms.

To be eligible for the study cows had to meet the following criteria: a projected calving date within the two-week trial period, being second lactation or greater, and no record of milk fever issues in previous lactations. All cows were physically assessed for body condition score (scale 1-5) with cows scoring $<2.75$ and $>3.25$ excluded form the trial. Cows were also assessed for lameness based on locomotion score (scale 15) with cows scoring $\geq 3$ being excluded from the trial. Multiparous cows were required to have valid on-farm records and have had a previous full-term pregnancy. Calving ease was also assessed. Cows with a calving ease score of $\geq 4$ were excluded from the trial, where a score of 4 is defined as a hard calving, including use of a calving jack and score 5 as requiring veterinary intervention, $\mathrm{C}$-section etc.

All eligible cows were then batched, and paired by parity into sub-groups. At calving, the cows within these sub groups (e.g. Farm $\mathrm{A}, 4^{\text {th }}$ lactation) were then randomly allocated into a control $(\mathrm{CON})$ or a treatment (BOL) group.

\subsection{Study Intervention}

Cows in the CON group received no oral bolus after calving, and cows in the BOL treatment group received two boluses. The first bolus was administered within 4 hours of calving, with an average time of 2 hours post-partum. The second bolus was then given to the cow at between 8 and 18 hours after calving, with an average time of 9.8 hours.

\subsection{Production Data Recording}

All calving and early lactation disease events were monitored and recorded on farm. Each farm is a member of the national milk testing programme with milk samples taken by an employee of the milk recording service supplier and then sent to an independent accredited laboratory for analysis. The results presented in this study are taken from a single day of production from the first official herd milk test for each farm. These results were used in order to determine the early lactation production performance of the cows in this trial. Two milk samples (morning and evening milking) were collected from each cow with milk volume recorded and the sample sent to the lab for analysis to determine the milk fat $\%$, milk protein $\%$ and somatic cell count levels for each cow.

\subsection{Sample Collection and Analysis}

Uterine discharge samples were collected by a veterinary surgeon at day 21 of lactation (+/- 3 days) and compared against the commonly-used Metricheck (0-3) scoring scale [21].

Two milk samples (disctint from those collected for the national milk testing programme) were taken from each cow at day 14 (+/-3days) and day 21 (+/-3days) of lactation and analysed immediately after milking, whilst still warm. Milk was analysed for Beta Hydroxy Butyrate (BHBA) levels (Keto-Test, Elanco Animal Health, Hampshire, UK) as per test instructions. The test reader was blinded as to the CON or BOL status of the cow.

\subsection{Statistical Analysis}

Data were analysed using the CORR, FREQ, and MIXED procedures of SAS (v9.4). Milk fat and protein yields were estimated by multiplying test-day milk yield with the respective percentages. Somatic cell score (SCS) was calculated as the $\log 2$ transformation of somatic cell count (SCC).

The statistical model for milk production parameters, SCC and SCS included fixed effects for treatment, lactation, treatment $\mathrm{x}$ lactation, days in milk and previous lactation yield. Farm was considered as the random effect. When analyzing Farm A and Farm B and C as separate trials farm was not considered as a random effect.

A chi-square analysis was conducted to determine if there were treatment differences between the difference score categories from the Metricheck test.

The milk BHBA data was analysed as a repeated measures model (as the correlation between BHBA on day 14 and 21 was 0.49). The statistical model for the BHBA considered treatment, lactation, treatment $\mathrm{x}$ lactation, day, treatment $\mathrm{x}$ day, days in milk, days dry and previous lactation yield. Farm was considered as the random effect.

Calving ease was not considered in the analysis, as there was not enough variation in this data as 99 of 103 cows had a calving ease of 1 .

\section{Results}

\subsection{Study Population and Farm Performance}

In total there were 252 eligible multiparous cows calving during the study period, of which 103 were enrolled in the study. 52 cows were in the BOL group and 51 cows were in CON group. Farm A had 56 eligible cows for the trial of which 38 were enrolled, contributing $37 \%$ of the trial cows. Farm B had 85 eligible cows of which 29 were enrolled in the trial, contributing $28 \%$ of the trial cows. Farm C had 111 eligible cows of which 36 were enrolled, contributing $35 \%$ of the trial cows.

The 3 selected farms demonstrated excellent performance in previous years in terms of production level, milk components, cow health and fertility. Overall herd 
performance for the 2018 spring calving season also showed that these herds were under excellent management and were not subject to higher than average levels of hypocalcaemia, and all 3 herds were well below threshold incidence levels for the major transition cow disorders [22] (Table 1).

Table 1. Farm data *[23].

\begin{tabular}{|c|c|c|c|c|}
\hline \multicolumn{2}{|l|}{2018 Trial Farms Data (combined) } & \multicolumn{2}{|c|}{2018 Trial Farms Disease Incidence (combined) } & \multirow{2}{*}{$\begin{array}{l}\text { Targeted Incidence Level } \\
<5 \%\end{array}$} \\
\hline Total Cows Calved 2018 & 899 & Milk Fever (clinical) & $2.3 \%$ & \\
\hline Cows Eligible for Trial & 252 & Retained Placenta & $1.4 \%$ & $<10 \%$ \\
\hline Cows Enrolled in Trial & 103 & Metritis * & $4.0 \%$ & $<10 \%$ \\
\hline Calving Interval & 369 days & Clinical Ketosis & $1.9 \%$ & $<5 \%$ \\
\hline
\end{tabular}

\subsection{Bolus Safety}

On all 3 farms, the boluses were administered with ease, and no adverse events associated with bolus administration were reported by those handling the cows in BOL groups.

\subsection{Adverse Health Events}

Recording of transition cow disorders (including retained placenta, metritis, left-displaced abomasum and ketosis) on the 3 farms demonstrated that the $\mathrm{CON}$ group of cows experienced a higher number of issues (6, or $11.7 \%$ ) compared to BOL cows (1, or $1.9 \%$ (Figure 1). These differences were not significant.

\subsection{Production Data}

All production data from the national milk recording scheme were collected and analysed as described. No significant differences between CON and BOL were detected, despite numerical trends in favour of the BOL group (Table 2).

Table 2. Least square means ( \pm standard error of the mean), the difference between the treatments, the standard error of the difference (SED) and the P-value for milk production data, and somatic cell count (SCC) for the entire data in the dataset.

\begin{tabular}{lllll}
\hline \multirow{2}{*}{ Trait } & Group & & & \\
\cline { 2 - 5 } & Control & Bolus & Difference & SED \\
\hline Milk Yield & $28.63(0.67)$ & $29.21(0.65)$ & 0.57 & 0.95 \\
Fat \% & $5.38(0.73)$ & $5.38(0.73)$ & 0.00 & 0.18 \\
Protein \% & $3.49(0.12)$ & $3.49(0.12)$ & 0.00 & 0.04 \\
Fat + Protein kg & $2.49(0.13)$ & $2.55(0.13)$ & 0.06 & 0.99 \\
Fat kg & $1.49(0.15)$ & $1.54(0.15)$ & 0.04 & 0.09 \\
Protein kg & $0.99(0.06)$ & $1.02(0.06$ & 0.02 & 0.06 \\
SCC ('000) & $212.77(64.54)$ & $176.77(63.46)$ & 36.00 & 0.03 \\
\hline
\end{tabular}

\subsection{Metricheck Scores}

With regard to the metricheck scoring performed at day 21 post-calving, there was no significant difference within score level and between treatments (Table 3).

Table 3. Chi-square analysis of the metricheck score on day 21 for control and bolus cows.

\begin{tabular}{llll}
\hline Metricheck Score Day 21 & Control & Bolus & Chi-Square \\
\hline 0 & 21 & 24 & $\mathrm{NS}^{1}$ \\
1 & 13 & 13 & $\mathrm{NS}$ \\
2 & 4 & 8 & $\mathrm{NS}$ \\
3 & 3 & 3 & $\mathrm{NS}$ \\
\hline
\end{tabular}

${ }^{1} \mathrm{NS}=$ non-significant.

\subsection{Status (Milk BHBA)}

Analysis of the Milk BHBA levels show that the BOL group had a significantly lower milk BHBA level compared to $\mathrm{CON}$ at day $14(\mathrm{P}<0.0001)$ and at day 21 of lactation $(\mathrm{P}<0.0001)$. Overall, the BOL cows had significantly lower BHBA concentrations than the CON cows as there was no treatment $\mathrm{x}$ day interaction (Figure 1 and Table 4).

Milk BHBA
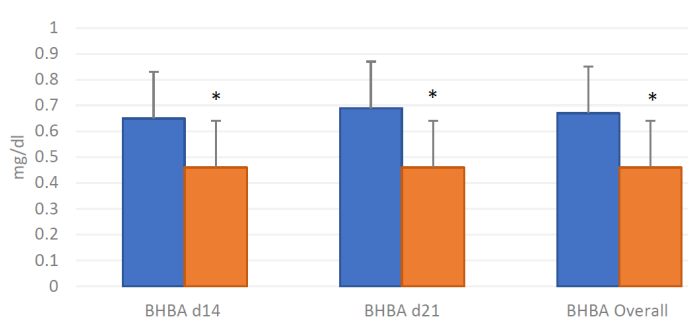

$\square \mathrm{CON} \square \mathrm{BOL}$

Figure 1. BHBA levels in milk \pm SEM. * indicates a significant difference between CON and BOL groups at both 14 and 21 days, and overall.

Table 4. Least square means ( \pm standard error of the mean) of BHBA on day 14 and day 21, and overall BHBA levels for the CON and BOL treatment groups.

\begin{tabular}{|c|c|c|c|c|c|c|c|c|}
\hline & Control & & Bolus & & Overall & & P-Value & \\
\hline & Day 14 & Day 21 & Day 14 & Day 21 & Control & Treatment & Group & Group x Day \\
\hline BHBA & $0.65 \mathrm{~A}(0.18)$ & $0.69 \mathrm{~B}(0.18)$ & $0.46 \mathrm{~A}(0.18)$ & $0.46 \mathrm{~A}(0.18)$ & $0.67(0.17)$ & $0.46(0.17)$ & $<0.0001$ & 0.86 \\
\hline
\end{tabular}

$\mathrm{A}-\mathrm{P}<0.001, \mathrm{~B}-\mathrm{P}<0.001$. 


\section{Discussion}

The purpose of this study was to evaluate both the safety and efficacy of a bolus at calving on transition cow disorders, fresh cow metabolic status, vaginal mucous score and early lactation milk production performance.

A number of key nutritional challenges to the transition cow were considered in the design of this bolus, such as; periparturient hypocalcaemia, a lack of available magnesium to enhance the uptake of calcium, negative energy balance and the intense oxidative challenge to the immune status of the cow in the periparturient period. The bolus was designed to address these issues with available calcium, magnesium and anti-oxidants.

The Cow Start Calcium bolus was designed to take a multifaceted approach to tackling some of the key issues that the cow faces at calving. The unique design of this bolus provides $65 \mathrm{~g}$ of calcium (specifically, 50\% more than standard boluses on the market), along with $4 \mathrm{~g}$ of Magnesium and rumen protected (encapsulated in a fat matrix) vitamin $\mathrm{E}$ and selenium in order to aid anti-oxidant function in the immediate post-partum period, a time where the cow faces the greatest challenge from reactive oxygen metabolites

The 3 trial farms selected have, in previous years, demonstrated an exemplary record in terms of transition cow health status and management skills (Table 1). These farms have consistently recorded metabolic issue levels that are well below targeted incidence levels and as such, typically do not experience many transition cow disorders. The trial was designed to see if the bolus could positively affect animal health in herds that already had excellent performance levels when compared to the targeted incidence level [22].

In all, the bolus was administered 104 times (52 cows $\times 2$ boluses) and no adverse effects associated with administering the bolus were recorded at any time. The farmers reported that the bolus was safely administered with ease and was well-tolerated by all animals, with no reports of any issues swallowing the bolus or any cases of regurgitation.

Whilst not significant, the record of the transition cow disorders show that the $\mathrm{CON}$ group experienced more transition cow disorders after calving with 6 events or $11.7 \%$ of the group, compared to 1 event or $1.9 \%$ of the BOL group.

The production data results give some interesting indications as to the performance of both groups of cows. Although these results were not statistically significant, there was a numerical trend in the treatment group towards higher levels of milk yield $(+0.6 \mathrm{~kg})$ without a reduction in milk component levels.

Vaginal mucous score, performed using the Metricheck method at day 21 (+/- 3days), show that there was no significant difference in the results between the treatment and control groups. All 3 herds demonstrated excellent and proactive management of cows at calving and all trial cows showed very low Metricheck scores, indicative that general uterine health was excellent across the board. This could have been predicted as there were very low incidence levels of dystocia, retained placenta or metritis amongst the cows $(0$ in BOL group and 6 or $11.7 \%$ in $\mathrm{CON}$ group), and these would be considered to be significant risk factors for deleterious uterine discharge scores.

The most interesting results of the trial was the significant reduction in milk BHBA levels of the treatment group at two timepoints post-calving, indicating a better early lactation metabolic status. For cows to have a lower level of milk BHBA with a similar or higher level of milk energy output is very interesting. Many nutrition remedies to improve metabolic status result in lower milk energy output [24].

This result would indicate that the bolus treatment group had a better metabolic status and this is supported by results in other studies which found a link between higher calcium status and lower blood BHBA levels $[8,9]$. Also, a previous study by $\mathrm{Wu}$ et al has shown higher dry matter intakes in cows supplemented on a daily basis with Lithothamnion spp. over the transition period [25]. The extra intakes after calving and into transition shown by $\mathrm{Wu}$ et al provide more dietary energy and protein for milk production, reducing the need to mobilise more energy from her fat stores, resulting in lower circulating energy metabolites, reflected in this study in the significantly lower milk BHBA levels in the treatment group. It has been proven that milk fever reduces feed intake [26].

\section{Conclusions}

The results of this trial show that the prophylactic treatment of a group of freshly calved cows in the second lactation or greater with two oral calcium and anti-oxidant boluses was a safe procedure. Furthermore, this intervention had a beneficial effect on the early lactation metabolic status of these cows as indicated by significantly lower milk BHBA levels at two postpartum timepoints. These findings indicate that the establishemnt of an early, optimal post-partum calcium status can have longer-lasting benefits during lactation, specifically, in terms of energy status. This is desirable in order to allow animals to reach their production potential while remaining healthy. The authors believe this work merits further investigations into both the mechanism of the observed findings, and the impact on production values throughout an entire lactation.

\section{Appendix}

\begin{tabular}{|c|c|c|c|}
\hline \multirow{2}{*}{\multicolumn{4}{|c|}{$\begin{array}{l}\text { Metricheck Details } \\
\text { https://dairyfocus.illinois.edu/content/simple-technique- } \\
\text { detect-metritis [21] } \\
\text { Supplemental Data }\end{array}$}} \\
\hline & & & \\
\hline \multirow{2}{*}{ Forage } & & & \\
\hline & Grass and Maize Silage & Grass Silage & Grass Silage \\
\hline Intakes & Ad-lib & Ad-lib & Ad-lib \\
\hline Dry Mater \% & 25.5 & 28.5 & 24.7 \\
\hline $\mathrm{D}$ Value $\%$ & 61 & 71 & 68 \\
\hline
\end{tabular}




\begin{tabular}{llll}
\hline \multirow{2}{*}{ Forage } & Farm A & Farm B & Farm C \\
\cline { 2 - 4 } & Grass and Maize Silage & Grass Silage & Grass Silage \\
\hline $\mathrm{ME}(\mathrm{MJ} / \mathrm{kg})$ & 9.8 & 11.3 & 10.9 \\
$\mathrm{NDF}(\mathrm{g} / \mathrm{kg})$ & 527 & 446 & 521 \\
$\mathrm{ADF}(\mathrm{g} / \mathrm{kg})$ & 366 & 327 & 382 \\
$\mathrm{CP}(\%)$ & 16.7 & 13.7 & 14.4 \\
\hline
\end{tabular}

\section{Acknowledgements}

Cow Start boluses were provided free of charge to the farms by Anchor Life Science Ltd. Anchor Life Science covered any costs incurred related to conducting the trial.

The authors would like to acknowledge the cooperation and efforts of the owners and staff at the 3 participating dairy farms for their commitment to conducting the trial (granting access to their cows, facilities and herd records, administering the boluses and record keeping).

The authors would also like to recognise the effort and support of the veterinary team and staff at Westgate Veterinary Clinic, Drogheda, Co. Louth.

\section{References}

[1] Goff, J. P., The monitoring, prevention, and treatment of milk fever and subclinical hypocalcemia in dairy cows. Vet J, 2008. 176 (1): p. 50-7.

[2] Liang, D., et al., Estimating US dairy clinical disease costs with a stochastic simulation model. J Dairy Sci, 2017. 100 (2): p. 1472-1486.

[3] DeGaris, P. J. and I. J. Lean, Milk fever in dairy cows: a review of pathophysiology and control principles. Vet J, 2008. 176 (1): p. 58-69.

[4] Mulligan, F. and M. Doherty, Production diseases: a major health, welfare and economic problem on dairy farms. Vet $\mathrm{J}$, 2008. 176 (1): p. 1-2.

[5] Curtis, C. R., et al., Association of parturient hypocalcemia with eight periparturient disorders in Holstein cows. J Am Vet Med Assoc, 1983. 183 (5): p. 559-61.

[6] Curtis, C. R., et al., Path analysis of dry period nutrition, postpartum metabolic and reproductive disorders, and mastitis in Holstein cows. J Dairy Sci, 1985. 68 (9): p. 2347-60.

[7] Whiteford, L. C. and I. M. Sheldon, Association between clinical hypocalcaemia and postpartum endometritis. Vet Rec, 2005. 157 (7): p. 202-3.

[8] Martinez, N., et al., Evaluation of peripartal calcium status, energetic profile, and neutrophil function in dairy cows at low or high risk of developing uterine disease. J Dairy Sci, 2012. 95 (12): p. 7158-72.

[9] Reinhardt, T. A., et al., Prevalence of subclinical hypocalcemia in dairy herds. Vet J, 2011.188 (1): p. 122-4.

[10] Roche, J. R., The incidence and control of hypocalcaemia in pasture-based systems. Acta Vet Scand Suppl, 2003. 97: p. $141-4$.
[11] Goff, J. P. and R. L. Horst, Oral administration of calcium salts for treatment of hypocalcemia in cattle. J Dairy Sci, 1993. 76 (1): p. 101-8.

[12] Oetzel, G. R., Effect of calcium chloride gel treatment in dairy cows on incidence of periparturient diseases. J Am Vet Med Assoc, 1996. 209 (5): p. 958-61.

[13] Rossi, C. C., R., Effects of a supplemental calcified marine algae bolus on blood calcium concentration, 2017.

[14] Bernard J. K.; Ellison B. N.; Taylor S. J.; Byrd, A. T., Impact of feeding a highly available source of calcium and magnesium on serum concentrations and urinary and excretion in pre-fresh dairy cattle., in American Dairy Science Association2018, Journal of Dairy Science: Knoxville, Tennessee. p. 318.

[15] Leonhard-Marek, S. and H. Martens, Effects of potassium on magnesium transport across rumen epithelium. Am J Physiol, 1996. 271 (6 Pt 1): p. G1034-8.

[16] Martin-Tereso, J. and H. Martens, Calcium and magnesium physiology and nutrition in relation to the prevention of milk fever and tetany (dietary management of macrominerals in preventing disease). Vet Clin North Am Food Anim Pract, 2014. 30 (3): p. 643-70.

[17] LeBlanc, S. J., et al., Peripartum serum vitamin E, retinol, and beta-carotene in dairy cattle and their associations with disease. J Dairy Sci, 2004. 87 (3): p. 609-19.

[18] Cebra, C. K., et al., The relationship between endogenous cortisol, blood micronutrients, and neutrophil function in postparturient Holstein cows. J Vet Intern Med, 2003. 17 (6): p. 902-7.

[19] Spears, J. W. and W. P. Weiss, Role of antioxidants and trace elements in health and immunity of transition dairy cows. Vet J, 2008. 176 (1): p. 70-6.

[20] Hogan, J. S., et al., Bovine neutrophil responses to parenteral vitamin E. J Dairy Sci, 1992. 75 (2): p. 399-405.

[21] Sheldon, I. M., The postpartum uterus. Vet Clin North Am Food Anim Pract, 2004. 20 (3): p. 569-91.

[22] Mulligan, F. J., et al., A herd health approach to dairy cow nutrition and production diseases of the transition cow. Anim Reprod Sci, 2006. 96 (3-4): p. 331-53.

[23] Kelton, D. F., K. D. Lissemore, and R. E. Martin, Recommendations for recording and calculating the incidence of selected clinical diseases of dairy cattle. J Dairy Sci, 1998. 81 (9): p. 2502-9.

[24] Whelan, S. J., et al., Short communication: Effect of dietary manipulation of crude protein content and nonfibrous-tofibrous-carbohydrate ratio on energy balance in early-lactation dairy cows. J Dairy Sci, 2014. 97 (11): p. 7220-4.

[25] Wu, Z., J. K. Bernard, and S. J. Taylor, Effect of feeding calcareous marine algae to Holstein cows prepartum or postpartum on serum metabolites and performance. J Dairy Sci, 2015.98 (7): p. 4629-39.

[26] Bareille, N., et al., Effects of health disorders on feed intake and milk production in dairy cows. Livestock production science, 2003.2003 v. 83 no. 1 (no. 1): p. pp. 53-62. 